\title{
Correction to: The Effect of Exercise for the Prevention of Bone Mass Loss After Bariatric Surgery: a Systematic Review and Meta-analysis
}

\author{
Florêncio Diniz-Sousa ${ }^{1,2} \cdot$ Giorjines Boppre $^{1,2} \cdot$ Lucas Veras $^{1,2} \cdot$ Alba Hernández-Martínez $^{3}$ · José Oliveira ${ }^{1,2}$. \\ Hélder Fonseca ${ }^{1,2}$
}

Published online: 25 January 2022

○) Springer Science+Business Media, LLC, part of Springer Nature 2022

\section{Correction to: Obesity Surgery \\ https://doi.org/10.1007/s11695-021-05873-1}

In the original article the word "Loss" was omitted from the article title - the title is correct here. Also, the funding details were inadvertently omitted:

Florêncio Diniz-Sousa was supported by the FCT (grant SFRH/BD/117622/2016), Giorjines Boppre was supported by the FCT (grant SFRH/BD/146976/2019), Lucas Veras was supported by the FCT (grant UI/BD/150673/2020), and Alba Hernández-Martínez was supported by the Plan Propio, Gerty Cori program from the University of Almería, Spain. The study was developed in the Research Center in Physical Activity, Health and Leisure (CIAFEL)-Faculty of Sports-University of Porto (FADEUP) (grant UID/ DTP/00617/2020), and the Laboratory for Integrative and Translational Research in Population Health (ITR) (grant LA/P/0064/2020).

Publisher's Note Springer Nature remains neutral with regard to jurisdictional claims in published maps and institutional affiliations.

The original article can be found online at https://doi.org/10.1007/ s11695-021-05873-1.

Florêncio Diniz-Sousa

joseflorenciosousa@gmail.com

1 Research Centre in Physical Activity, Health and Leisure (CIAFEL), Faculty of Sport, University of Porto, Rua Dr. Plácido Costa, 91, 4200-450 Porto, Portugal

2 Laboratory for Integrative and Translational Research in Population Health (ITR), Porto, Portugal

3 Department of Education, Faculty of Education Sciences, SPORT Research Group (CTS-1024), CERNEP Research Centre, University of Almería, Almería, Spain 